\section{$020-021$}

\section{Noticias y comentarios}

\section{PH48 - Abril 2004}

y punto de referencia para los profesionales de nuestro país.

En sintesis APASub se configura como:

> Asociación de profesionales en torno a la Arqueología Subacuática.

> Alternativa no gubernamental sin ánimo de lucro. > Soporte y coordinación entre técnicos de distintas comunidades autónomas, para la difusión e intercambio de información.

> Difusión y protección del patrimonio subacuático. $>$ Coordinación de actividades en beneficio de la Arqueología Subacuática.

> Organización de eventos para la difusión del patrimonio subacuático.

Confiamos en que esta Asociación agrupe a los técnicos que actualmente gestionan el patrimonio y a los jóvenes que lo harán el día de mañana, así como que renueve las ilusiones a los profesionales que nos precedieron, y que, de ahora en adelante, podamos contar con su experiencia para una efectiva investigación, protección y difusión del patrimonio cultural subacuático.

Más información:

APASub

Web: www.arqueologiasubacuatica.org

Correo-e.: administracion@apasub.org

Carlos Cabrera Tejedor

Presidente de APASub

\title{
La asociación OIKOS publica el primer número de Cuadernos de Economía de la Cultura
}

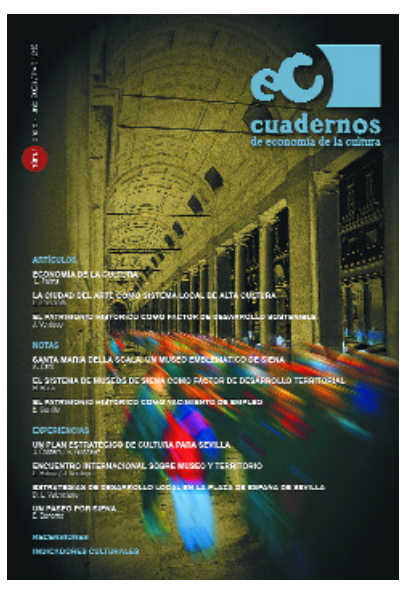

Formada por un grupo de profesionales de amplio espectro disciplinar que comparten y desean promover un foro abierto a la expresión de las ideas, la participación y la creatividad como contribución independiente al progreso de Andalucia, la asociación OIKOS se concibe como un observatorio andaluz enfocado al análisis de tendencias e instrumento de conocimiento relacionado con los aspectos culturales desde un punto de vista económico.

Uno de los fines primordiales de la asociación, recogido en sus estatutos, es "difundir a través de publicaciones en sus distintos formatos investigaciones y opinión sobre el mundo de la cultura y su relación con el desarrollo económico". En esta línea, OIKOS acaba de editar el número 1 de la revista Cuadernos de Economía de la Cultura (enerojunio 2003), una publicación que se establece como medio fundamental en el que exponer a la discusión pública los trabajos que desde la asociación y su entorno abordan un mejor conocimiento de la disciplina Economía de la Cultura. Además, la revista está abierta a la incorporación de contribuciones ajenas a la asociación y que encajen en los objetivos de la misma y en el perfil editorial de la revista.

Entendemos que una buena gestión de la cultura puede y debe producir beneficios económicos. Además, el uso de herramientas del análisis económico puede ayudarnos a entender mejor las claves de funcionamiento de un sector que, tanto desde lo privado como desde lo público, se erige en una pieza clave del Estado del Bienestar. La cultura, efectivamente, ha de concebirse como un factor de desarrollo pero también de cohesión social. Estos objetivos deben conseguirse mediante un proceso de democratización cultural que pretendemos estimular desde la revista.
La revista Cuadernos de Economía de la Cultura viene a llenar un vacío entre las publicaciones periódicas de ámbito nacional. Al mismo tiempo, desea servir de vehículo para la comparación, el contraste y la cooperación que fortalezcan vínculos regionales y transnacionales. La información contenida en sus páginas pretende ejercer como instrumento para la toma de decisiones de los gestores culturales, las instancias públicas y los investigadores.

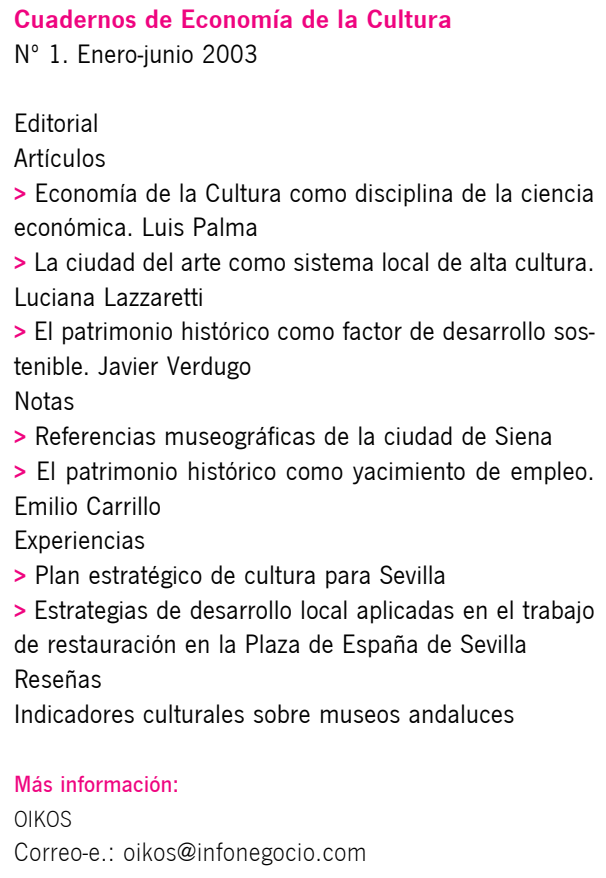

$>$ Economía de la Cultura como disciplina de la ciencia económica. Luis Palma

$>$ La ciudad del arte como sistema local de alta cultura. Luciana Lazzaretti

$>$ El patrimonio histórico como factor de desarrollo sostenible. Javier Verdugo

Notas

$>$ Referencias museográficas de la ciudad de Siena

$>$ El patrimonio histórico como yacimiento de empleo. Emilio Carrillo

Experiencias

$>$ Plan estratégico de cultura para Sevilla

$>$ Estrategias de desarrollo local aplicadas en el trabajo de restauración en la Plaza de España de Sevilla Reseñas

Indicadores culturales sobre museos andaluces

Más información

OIKOS

Correo-e.: oikos@infonegocio.com

\section{José María Medianero Hernández}

Luis Palma Martos

Miembros de OIKOS

Universidad de Sevilla 